\title{
A formação e sua sombra
}

\author{
Newton Ramos-de-Oliveira
}

É do filósofo francês Merleau-Ponty, o conceito de "sombra do filósofo". A sombra de um filósofo indica todos os conceitos e julgamentos que, ao longo dos anos, décadas e séculos, vão se agregando em torno daquele filósofo. Trata-se de uma espécie de plantas parasitárias que vão se enroscando em torno de um vegetal matriz e acabam, muitas vezes, toldando a visão do tronco essencial. $\mathrm{O}$ agregado passa a conspurcar a compreensão. A história registra muitos e muitos exemplos da "sombra". Irremovíveis quanto mais recuados no tempo. Citemos dois bem conhecidos: o conceito de "amor platônico", que Platão jamais conheceu e a frase "credo quia absurdum est" erroneamente atribuída a Agostinho. A sombra, que se agarra ao filósofo, se enrodilha nas idéias que em torno dele se movimentam. Ou seja, invadem o filósofo pelas frestas de seus conceitos.

Theodor Adorno e Max Horkheimer trataram do conceito de indústria cultural ao longo do texto básico "Dialética do Esclarecimento", em 1957. Dada a centralidade do conceito, Adorno a ele retornou em muitas passagens de seus textos posteriores, que abrangem diferentes áreas de conhecimento, desde filosofia e sociologia até crítica literária e de música. Mas, com certeza o retorno mais interessante ao tema seja o artigo "A indústria cultural reexaminada". Se este é o retorno, a reafirmação e atualização mais interessante, sua complementação básica está no "Teoria da Semiformação" (1)

Por que Adorno terá retornado ao tema da "indústria cultural" ? Talvez, eis nossa hipótese, porque o termo tenha se alastrado pelos mais diversos textos dados ao público. Em outros termos, Adorno viu-se obrigado a retornar ao conceito justamente porque o conceito havia encontrado terreno propício para difundir-se. E quanto mais difuso ... mas correndo o perigo real de ser deformado, destituído de sua força original. Alguns desses perigos acontecem a partir de opositores, mas vários nascem nos próprios autores que assumem ou tentam assumir uma posição frankfurtiana. No âmbito desse texto, tentaremos comentar algumas "sombras" a respeito do par "indústria cultural-semiformação" e o faremos por um lado de que conheço algo por experiência de vida e de reflexão: o domínio da educação.

É e não é fácil assumir como objeto material a educação e como objeto formal a reflexão sobre indústria cultural e semiformação. Parte da dificuldade vem da própria complexidade dos dois conceitos adornianos, mas parte substancial vem de algumas características intrínsecas da própria educação. Destacaremos sobre a educação:

* urgência de ação - trata-se de um fazer, uma série de ações imediatas e diretas. A inevitabilidade de agir, coloca sob risco a correta avaliação dos aspectos que se acumulam ao longo do cotidiano nas salas de aula

* campo de duas dimensões concorrentes: uma especialização imersa num campo que, em muitos sentidos, é ultrapassada justamente pela mídia, portadora maior da 
indústria cultural e da semiformação. A situação tem dupla face: a educação difusa é exercida em todos os momentos e lugares e sufoca o cidadão em todas as suas faixas de idade; por outro lado, a educação escolar é especializada, diretamente dotada de uma certa e dinâmica autoridade: educar é um processo mais complexo do que a informação requentada dos meios de comunicação de massa.

* inércia: as rápidas mudanças do campo sócio-cultural demoram a se integrarem nas salas de aula como instrumentos e fins. É bem verdade, no entanto, que chegam rapidamente quando adotadas como modismos, mas essa aparente integração desaparece substituída pelas novidades posteriores - ou seja, circulam realmente como tendências da moda. Ontem foi Paulo Freire, Gramsci ou Saviani? Hoje é Vigotskii e Piaget? Quem será amanhã? O cinema tornou-se, desde o século passado, uma realidade cotidiana: como a linguagem fílmica é tratada reflexivamente nas escolas? A sociedade é revirada pelas rapidíssimas mudanças tecnológicas, mas a escola forma analfabetos tecnológicos.

* tendência a encapsular-se para não se dissolver. Há, como nas demais características, campos de forças opostas: um movimento para assimilar a escola à família e à comunidade e outro de defesa e de afastamento. Em vez de a escola irradiar-se ao exterior, o exterior é (mal) assimilado pela escola. Temos, então, o professor-animador televisivo, o homem-show, o comentarista superficial. Temos também o filme horripilantemente boçal ou superficial para "matar" a aula, que o professor não teve tempo de preparar ou que a isso se recusou naquele dia letivo.

É nesse universo de forças conflitantes que a escola pretende assumir seu papel sócio-cultural - e assume, seja por ação, seja por inação.

As objeções que se fazem ao conceito de indústria cultural são bem conhecidas e repetitivas. A postura de Adorno seria elitista e negligenciaria um fato evidente: de que a arte nunca teria alcançado sua autonomia. A arte teria sido sempre através dos séculos e em todos os espaços "patrocinada" ou "direcionada" a interesses particulares de indivíduos ou grupos.

O que seria um elitismo? A suposição de que cabe apenas a uma vanguarda o gozo de determinados bens culturais? Mas a denúncia da indústria cultural e da semiformação como orquestradas pelo fetichismo do mercado não é uma resistência heróica contra poderes hegemônicos que oprimem a humanidade e cortam-lhe os caminhos da libertação e da humanização? Não são esses fatos impositivos, muitas vezes evidentes e outras vezes sub-reptícios, que exercem ações nefastas como a difusão do pensamento único e a ocultação de um novo horizonte, de um espaço utópico? Se a tradicional bebida infantil conhecida como "sangria", isto é, dissolução do vinho por água, é vendida a todos os instantes como vinho, denunciar essa fraude é elitismo e deveremos todos beber desse embuste?

Por outro lado, se a Capela Sistina, por exemplo, construída no século XV pelos arquitetos Baccio Pontelli e Giovannino de'Dolci e pinturas de parede por um conjunto de artistas e toda essa empresa teve patrocínio do Papa Sexto IV, se no 
século seguinte, Michelangelo Buonarroti refez a pintura do teto sob patrocínio do Papa Júlio II, sabemos todos que a possível interferência de ambos os papas não atingiu jamais o cerne da arte de Michelangelo, a sua técnica, as suas inovações, o seu estilo. Já o mercado, que se impôs cada vez mais violento à medida que o capitalismo se firmava e se metamorfoseava historicamente em concorrencial, monopolista ou globalizante, invade o íntimo da criação artística. O fetichismo da mercadoria se insere pelos poros do próprio artista e contradiz a realidade da arte. Só é capaz de compreender esse movimento onipresentemente invasivo quem é capaz de compreender e usufruir da arte. Quem não conhece do vinho, aceita a sangria. Quem não entra na boléia adora carona na traseira do caminhão. Mas não é elitista quem quer todos usufruindo do que vale a pena ser usufruído. A formação exalta, quer incluir, não se aliena, não se exclui.

Outro aspecto sobre o qual se deve refletir é a confusão entre indústria cultural semiformação com programas e obras de evidente mal gosto e baixo nível. Criticar programas de televisão em que se defende a pena de morte a todos os instantes ou os comentários escandalosos a respeito de personalidades absolutamente insignificantes ou, ainda, músicas pobres de melodia e de letras do tipo que repetem ad nauseam uma frase musical tipo "amor, I love you" não é exatamente denunciar a indústria cultural e a semiformação. Obras e programas desse tipo sempre existiram e são apenas exemplos do popularesco, daquilo que está abaixo de qualquer gosto mediano. Fenômenos desse tipo indicam o máximo da patologia - algo tão evidente que, na verdade, nem oferece perigo maior à arte ou ao conhecimento. São desprezíveis e ocultam o perigo maior. O que revela o eixo indústria cultural- semiformação é o que acaba sendo considerado de valor para os gostos deturpados da maioria da população que se julga bem formada. Entram nessa categoria as novelas televisivas, os romances best-sellers, os que ganharam Oscars e quejandos.

Mas ... é preciso indicar dois fatos aparentemente contraditórios: (a) nada escapa à sanha da indústria cultural e da semicultura e (b) há graus diferenciados nos pólos opostos indústria cultural-semiformação e arte + conhecimento significativo.

Vivemos num mundo configurado pelo mercado e por seu fetichismo. E o que é pior, o ritmo de deformação cultural imposto e assimilado pela sociedade é crescente. Obras de caracterização não-artística, não-cultural são rejeitadas de início, mas, aos poucos, vão se tornando a regra geral, de algo rejeitado passam a algo tolerado e desse estágio a algo procurado e depois a algo exaltado! De início, diríamos que de aproximadamente uma geração, a qualidade se dissolvia. Talvez hoje possamos dizer que essa impregnação perversa se firma de década a década. Isso no lado mais espalhafatoso, mas sejamos alertas ao julgarmos que algo escape a este imã poderoso que é hoje o mercado.

Mas, o que se faz necessário não é o anátema, a condenação indiscriminada. Como igualar obras de caráter bem diverso? Rejeitaríamos, então, tudo o que se faz e se lança ao público? Não exatamente. Adorno deu entrevistas e participou de debates radiofônicos, exaltou o papel da mídia para uma ampla e forte ação sobre o conservadorismo autoritário encontrável em especial nos meios rurais. Elegeu, 
também, seus músicos e escritores significativos em amplas resenhas críticas. $\mathrm{O}$ trabalho docente e individual é o de penetrar no cerne da configuração fundoforma para discernir os graus de deformação que trazem por impacto do deusmercado. A resistência se impõe e generalizar a condenação seria ato extremamente hipócrita quando em nosso cotidiano exaltamos músicas populares, filmes assistidos em casa ou em cinemas, livros adquiridos e saboreados com prazer. Como condenar uma obra como "Crônica de uma morte anunciada", de Gabriel Garcia Marques; ou peças como "A morte do caixeiro viajante", de Arthur Miller; ou "Estranho interlúdio", de Eugene O'Neil; curta-metragens como "Witness"(2) , toda a obra de Kafka ou Proust?

Mas a indústria cultural não deixa território intacto: mesmo — ou mesmo "até" — as obras melhores são as mais atacadas, sofrem processos de deglutição.

Para indicar um desses processos quero comentar o romance "Crônica de uma morte anunciada" comparando-o com sua versão cinematográfica. A grande proeza de Gabriel Garcia Marques no romance é conseguir reconstituir o tom clássico da tragédia. Segundo alguns críticos, a tragédia, nascida na Grécia, num conjunto de circunstâncias que colocam o ser humano sozinho e sabendo-se impotente, mas levantando-se contra as forças ignotas e inalcançáveis dos deuses. Com o advento do cristianismo, religião do perdão trazido por Cristo, a tragédia perde sua sustentação maior, que é o desamparo do indivíduo diante de uma realidade que o suplanta inexoravelmente. Já não temos, no contexto cristão, o indivíduo isolado, desamparado. Como se constrói a "Crônica"? Num pequeno povoado latino-americano ocorre um noivado entre Ângela Vicário e Bayardo San Román, um belo, rico e misterioso forasteiro. Na noite de núpcias, o noivo descobre que Ângela não é virgem. Devolvida à família e pressionada afirma que teria sido desvirginada por um rapaz da aldeia, Santiago Nasar. Em todo o romance tudo aponta para desmentir tal acusação. $\mathrm{O}$ tabu da virgindade paira sobre todas as consciências da aldeia e, ao mesmo tempo, todos procuram de uma maneira ou outra avisá-lo de que os irmãos gêmeos da noiva rejeitada vão matá-lo a golpe de facões. O universo trágico está armado: há uma força superior inultrapassável, o tabu da virgindade; há indicações claríssimas sobre o destino inflexível, mas tais avisos deixam de chegar ao destinatário e este morre, como tinha que ser. A aldeia se reorganiza, a noiva está redimida, os cunhados assassinos lavaram a honra familiar. O romance ainda revela que Ângela, apaixonada pelo marido que já abandonou a povoação, escreve-lhe cartas semanais "sem quartel" durante 17 anos.

Em um meio-dia de agosto, enquanto bordava com as amigas, sentiu que alguém chegava à sua porta /.../ Bayardo San Román deu um passo à frente, sem se preocupar com as outras bordadeiras atônitas, e pôs os alforges na máquina.

- Bem - disse - aqui estou.

Levava a mala da roupa para ficar e outra mala igual com quase duas mil cartas que ela lhe escrevera. Estavam ordenadas por suas datas, em pacotes amarrados com fitas coloridas, e todas sem abrir. (MARQUES, 1981: p. 140-141) 
Este parágrafo, embora não seja o final do romance, pois esse segue uma ordem psicológica de narração e não linear, marca a reconstituição do universo dos tabus da aldeia. Pressuposto fica que a expiação será ultrapassada, mas esse desfecho vem apenas sugerido, encaixado coerentemente com o sentido geral da tragédia.

O romance foi convertido a filme e em filmes a indústria cultural, que tem como figura central o produtor, aquele que investe capital e deseja um retorno bem significativo, faz uma pequena alteração: as cartas não estão mais organizadas e embrulhadas em pacotes. Continuam não abertas, mas são espalhadas pelo terreno em torno da casa que seria do casal. Ângela se aproxima e os dois se abraçam. Tudo bem com eles. Tudo mal com a arte.

Como comenta a revista "New German Critique" em 1963 (O'CONNOR, 2000: 231):

A cultura, afirma Adorno, era uma área de protesto em que a grande arte provocava a consciência das dificuldades existenciais. Agora, no entanto, a indústria cultural busca a adaptação. Adorno, comenta com brilhantismo, sugere até que consciência e adaptação tornaram-se idênticas. Adorno não está sugerindo que os produtos da indústria cultural sejam consoladores no sentido de que nos afastam da miséria de todos os dias, pois argumenta pela totalidade de sua Teoria Crítica que a miséria da organização social nem mais existe.A indústria cultural encoraja seus consumidores a ver a sociedade como entidade positiva e natural. A simplicidade e a rígida inalterabilidade de seus produtos assemelham-se à sociedade reificada e, como tal, não oferece alternativas nem qualquer espaço que permita criticar a reificação.

O que pode parecer detalhe é essencial. No romance há uma coerência reveladora, tudo se encaminha para o que se preve. $\mathrm{O}$ tabu desorganiza e o atraso reorganiza. O noivo coleciona as cartas como intactas porque conhece-lhes o conteúdo mesmo sem ler - é seu ato final de vingança e de honra. No filme, a cena de cartas esparramadas pelo terreno é mais eficaz como imagem, mas contraria o ato seguinte, que, culmina, no absurdo de uma reconciliação imediata, happy end que ao satisfazer a "ordem constituída" reforça a inexorabilidade não do tabu, que poderia e deveria ser combatido e ultrapassado, mas como inexorabilidade do sistema social e impotência dos indivíduos diante da opressão.

Aristóteles afirmava que escrevemos para nos compreendermos. A indústria cultural existe para que não compreendamos. Nem a nós, nem a sociedade. Nem o pensamento crítico e reflexivo, nem a utopia da libertação.

$\mathrm{Na}$ indústria cultural

os conceitos que martela aos seres humanos são sempre aqueles do status quo. Não são questionados ou analisados, mas pressupostos de uma maneira adialética ainda que destituídos de substância para os que os aceitam. Em contraste com o conceito kantiano, o imperativo categórico da indústria cultural não compartilha qualquer vínculo com a liberdade. Proclama: você deve se conformar e nem 
sequer orienta a quê se deva conformar; de qualquer maneira é um conformar-se com o existente e o que quer que pensem deter força e onipotência. O poder ideológico da indústria cultural é tal que a conformidade substitui a consciência. A ordem que dela emana nunca se coloca em confronto com o que alega ser ou com os interesses reais dos seres humanos. (Adorno in O'CONNOR, 2000: 236).

A linguagem literária e a linguagem fílmica têm seus próprios cânones artísticos, mas a submissão ao mercado é muito mais forte no cinema do que na imprensa. Há, na edição de obras literárias, o poder da indústria cultural. Calcula-se, nesse início do século XXI que anualmente são editados 10 bilhões de livros e, sabemos, que autores medíocres ocupam a lista de best sellers meses e meses seguidos, arrecadando enormes somas de capital. Mas o cinema investe muito mais e, portanto, exige muito mais fortes garantias de retorno do capital investido.

Portanto, o cinema não pode arriscar-se ao novo. O contrário acontece com a arte: a arte alimenta-se de uma tradição que, ao mesmo tempo, lhe serve de amparo $e$ de oposição. A arte tem que inserir-se na tradição para melhor negá-la: é uma empresa de ousadia, de risco. Uma atividade radical da criatividade humana. Como se vê, indústria cultural e arte estão em pólos antagônicos.

E como fica diante dessa dicotomia a educação? Num sentido mais realista, a educação que deveria ter como meta a formação, acaba por adotar a de-formação. Os exemplos são abundantes. Um deles diz respeito aos livros exigidos nos exames vestibulares: cada universidade relaciona anual ou bienalmente cerca de 10 livros considerados básicos de nossa literatura. Somos historicamente um país de poucas leituras. A imprensa só nos foi permitida com a vinda da família real portuguesa $e$ as editoras apenas no primeiro reinado. Se os europeus passam da imprensa à televisão, os brasileiros passamos do nada ao televisivo. Nessa corrente, o que fazem os cursinhos com os livros obrigatórios? Resumos. Perde-se, com isso, o cerne da literatura como arte. A união forma-conteúdo, que é o sangue da obra literária, se fragmenta e o aluno recebe um Ersatz, um simulacro. O que lhes é ensinado como literatura? Um simples desenrolar de historietas que envolvem personagens descaracterizados. Se mais tarde, esses alunos vierem a se interessar pela literatura será não por causa dos estudos escolares, mas apesar desses estudos.

Florestan Fernandes afirmou concisamente que a revolução de 1964 tinha tido como um de seus objetivos principais tornar a educação um não-valor. Essa frase impressiona pela profunda verdade. Enquanto professores ingênuos imaginam-se no domínio do ensino em sala de aulas, a pergunta de Marx continua angustiante: "quem educa o educador" ? A mídia, ou melhor, a indústria cultural educa o educador - na verdade, "educa" a nós todos! E a educação (formal, escolarizada) tende a tornar se um não-valor.

E quem exerce essa atividade que se destitui de valor? Um profissional valorizado pelo público, mas subvalorizado pela sistema neoliberal e globalizante no modelo estadunidense. Um exemplo a mais, dentre os inúmeros que nos assolam, é dado pela medida da Secretaria da Educação do Estado de São Paulo que criou, agora, um tipo de profissional iniciante a que poderíamos chamar de 'professor mutante'. 
O professor recém licenciado procura uma escola estadual e, se cair nas boas graças do Diretor, consegue ser registrado como "professor com sede" naquela determinada escola. A partir desse título, o professor passa a ser disponível para preencher ausências nas escolas em que quiser e será chamado para a disciplina e a série que as escolas o requisitem. Um licenciado em História, por exemplo, poderá ser convocado para lecionar na escola "A" uma aula de Educação Artística para a 5 a série e outra de Inglês para a 8a série; se continuar "com sorte" estará à tarde dando aulas de outras matérias para outras séries. É, portanto, um professor volante e mutante, um caixeiro da educação. Ou seja, a Secretaria da Educação paulista desprofissionaliza o professor, que se vê desmoralizado perante alunos e - isto é muito pior - também perante seus próprios olhos. Também o Governo Federal, através do seu Ministério da Educação (MEC) adotou para o país uma medida no mesmo sentido. Trata-se dos chamados "temas transversais" que constam dos Parâmetros Curriculares. Uma série de temas, como sexo, por exemplo, são colocados como assuntos que devem ser tratados por todos os professores do estabelecimento do ensino. Observe-se que os temas eleitos como transversais são sempre importantes e ... pertencentes ao campo das ciências humanas. Por trás dessa temática assim universalizada nos currículos escolares está a convicção de que temas de ciências humanas não exigem formação especializada: todos sabem. Trata-se de um assunto dependente das opiniões do senso comum, temas sobre os quais quaisquer cidadãos podem com, com igual competência, discorrer. Procure descobrir um "tema transversal" que pertença às ciências chamadas exatas ou às biológicas. Se a Secretaria da Educação do Estado de São Paulo desmoraliza o professor diante dos alunos e de si mesmos, o Governo Federal desmoraliza a própria noção de ciências humanas.

Eis, aí, o professor sem valor e a temática humana como um não-valores. Eis aí a educação tornada um não-valor.

Se, ao longo das últimas décadas, a educação brasileira vem sendo passo a passo desvalorizada, como reage a sociedade brasileira?

Há os heróicos cidadãos que exercem resistência aos descalabros do ensino oficial; há os que desistem da escola pública e se dedicam às escolas privadas; há os que desistem das escolas privadas e encaminham seus jovens filhos ao ensino ou aperfeiçoamento no exterior. Há, também, os que desistem e se acomodam. Recentemente estudos comparativos da UNESCO quanto ao conhecimento dos alunos constatou que apenas $25 \%$ de nossos estudantes adolescentes formados são capazes de ler um texto simples e dele conseguem relacionar um mínimo de duas idéias... Esse é o aluno que conseguiu cursar todas as séries do ensino fundamental e médio.

A indústria cultural não faz tudo convergir para a conformidade? Somos um país jovem no concerto mundial. Tivemos mais de três séculos de escravidão e de proibição de montar editoras no país. Temos uma desigualdade social absurda. $\mathrm{O}$ hábito da leitura não havia conseguido firmar-se na população quando esta foi tomada de assalto pela atração dócil dos programas de televisão e da profusão de imagens. 
Diante desse quadro de semiformação, de formação travada, temos duas reações que podem conviver: a exaltação da não-cultura e o conformismo. Conviver por quê? Porque se alimentam mutuamente.

Automóveis desfilam por nosso trânsito com frases erradas, nos estádios de futebol, paixão nacional, torcedores sustentam cartazes com absurdos ortográficos e sintáticos. Não se trata de descuido, mas de afirmação feita de propósito. É como se seus autores dissessem em alto e em bom som: "como fracassamos — nós e vocês como conjunto - na construção cultura, agora vamos exaltar nossa ignorância! A língua portuguesa, que representa nossa alma, torna-se instrumento de uma resistência equivocada $e$ conformista.

O educador israelense Ilan Gur-Ze'ev cunhou a expressão "escola padronizadora", ou seja, a aquela que despersonaliza seus estudantes, adaptando-os não para serem bons cidadãos mas para submeterem-se à opressão como cidadãos bons, isto é, adultos inocentes, coniventes, adaptados. Desiludidos. Derrotados.

Como se vê por esses rápidos flashes, a indústria cultural que assola o mundo, assola-nos com uma violência e onipresença inusitadas.

Adorno, no texto "Teoria da Semiformação" (cit.), distingue o semiformado do cidadão comum, que não domina bens culturais, mas que tem um certo bom senso, uma certa malícia, uma certa experiência do mundo real que o leva a duvidar dos absurdos que semiformados queiram passar-lhes. Acrescenta o filósofo frankfurtiano que, no entanto, o campo na Alemanha já estava sendo progressivamente conquistado pelo espírito da semiformação cultural. Como Adorno analisaria a situação acima descrita a que poderíamos chamar de "exaltação do não-saber"? Identificando o semiformado como aquele que "está excluído da cultura e que, ao mesmo tempo, com ela concorda" (3), como classificaria o pequeno burguês brasileiro que acintosamente "discorda" da cultura? Quais mecanismos psíquicos estão aí atuantes? Em qual tipo de sociedade eles se manifestam?

"Os dados publicados recentemente (Atlas da exclusão social - Os ricos no Brasil, ed. Cortez) reiteram como no Brasil - e no Rio de Janeiro - temos a sociedade mais injusta do mundo, em que a distribuição das riquezas materiais e culturais é a pior do universo" (Sader in JORNAL DO BRASIL 2004)

Como se vê, o conceito de indústria cultural e sua contra-parte, a semiformação, impõem-se como cada vez mais presentes em todo o mundo e com excessivo peso em nossa sociedade injusta. Devem constituir, portanto, objeto das reflexões de todos os que se dedicam à educação, ou melhor, a todos que desejam um país melhor num mundo melhor.

\section{Referências Bibliográficas}


ADORNO, Theodor W. e HORKHEIMER, Max - Dialética do Esclarecimento: fragmentos filosóficos. Tradução de Guido Antônio de Almeida. Rio de Janeiro: Zahar, 1986.

ADORNO, Theodor W.- Teoria da Semicultura, tradução de Newton Ramos-deOliveira, Bruno Pucci, Claudia B. M. Abreu, revisão de Paula Ramos-de-Oliveira. In Educação e Sociedade: revista de ciência da educação, 56, Ano XVII, dezembro de 1996: 388-411. Fiz recentemente uma atualização comentada desse texto, mas aguardamos autorização da Suhrkamp para publicá-las talvez no livro "Ensaios Frankfurtianos" a sair ainda neste ano de 2004.

ADORNO, Theodor W. - Culture Industry Reconsidered in O'Connor (ed.) The Adorno Reader, Oxford (U.K.): Blackwell Publishers, 2000. Pags. 230-238.

MARQUES, Gabriel Garcia. - Crônica de uma morte anunciada. Tradução de Remy Orga, filho. 21a. edição. Rio de Janeiro: Editora Record, 1997.

SADER, Emir - "Espaços públicos ou muros privatizantes" in Jornal do Brasil, Rio de Janeiro, 18 de abril de 2004 http://jbonline.terra.com.br/

(1)ADORNO, Theodor W.- "Teoria da Semicultura", tradução de Newton-Ramosde Oliveira, Bruno Pucci, Claudia B. M. Abreu, revisão de Paula Ramos-deOliveira. In Educação e Sociedade: revista de ciência da educação, 56, Ano XVII, dezembro de 1996: 388-411. Fiz recentemente uma atualização comentada desse texto, mas aguardamos autorização da Suhrkamp para publicá-las talvez no livro "Ensaios Frankfurtianos" a sair ainda neste ano de 2004.

(2)"Witness" foi escrito e dirigido por Cris Gerolmo; fotografado por Peter Lang; editado por William Goldenberg; musicado por John Barry; Apoio pelo "The Simon Weisenthal Center e pelo "The Anti-defamation League". Chantecler Films. Inc., 1992.

(3)Cf. Theodor W. Adorno "Teoria da Semiformação", in O'Connor, Brian, The Adorno Reader, pág. 24. 